\title{
Study the Effects of Free Vibration and Effective Elastic Properties with Variation of Layer Orientation of Symmetric Laminate Plates
}

\author{
K. Pradeep Chand ${ }^{1}$, K. Chaitanya ${ }^{2}$ \\ ${ }^{1}$ Vignan's University, School of Mechanical Engineering, Vadlamudi, Guntur-522213, Andhra Pradesh, India \\ ${ }^{2}$ Vignan's University, School of Mechanical Engineering, Vadlamudi, Guntur-522213, Andhra Pradesh, India
}

\begin{abstract}
Composite materials are play a key role in a aerospace structures. For those structures, it is required a high natural frequency, low weight and high strength etc. Composite materials are full filling these properties. The layer orientation, aspect ratio, laminate thickness, boundary conditions and type of material are key parameters to determine the natural frequency. A rectangular composite (graphite/epoxy) symmetric laminate plate having 4-layers with simply supported boundary conditions are assumed. With the help of MATLAB programming hundred laminates (samples) of 10 units varying layup configuration are developed. For each sample, the natural frequency and Effective elastic properties are calculated by using Classical Laminate Plate Theory (CLPT) and Navier solution in MATLAB. Analytical results of each sample, the natural frequency and Effective elastic properties are compared to the AUTODESK Simulation composite design software. Investigate, for which layup configuration shows the highest and lowest natural frequency. And how the Effective elastic properties are varies with layer orientation.
\end{abstract}

Keywords: Symmetric laminate, free vibration, CLPT, Effective elastic properties, MATLAB

\section{Introduction}

Composites have properties which are not achieved by either of the constituent's materials alone. These are having properties like high strength to low weight ratio, long live and inexpensive to produce. These are improving structures quality of life. These reasons put composites in service like Aerospace structures, Automobiles, Boats, Pipe lines, Buildings, Bridges, Roads. Free vibration analysis of plate is very important in the field of structural Engineering because of its wide application in practical life. Free vibration of the plate depends greatly on its thickness, aspect ratios (a/b) and the boundary conditions. Laminate properties are very important to do the further analysis like stress analysis and buckling analysis.

The literature survey shows that the free vibration of flat plates has been extensively studied in the past, and various textbooks and monographs have appeared on vibration of isotropic plates [4-7]and on composite plates[1-3,7] under different boundary conditions. There are so many theory's to determine the free vibration of composite plates.

\section{Theory of laminated plates and Natural frequency}

\subsection{Analysis of laminated composite plates}

From the mechanics of composite plates and shells by j.n Reddy [1] and mechanics of composite materials by Robert M.Jones[2] the classical laminate plate theory (CLPT) is used to analyze the mechanical behavior of the composite laminated plates. We assume that plane stress condition is valid for each ply.
This theory is the extension of the classical plate theory. The plate response is influenced by the fiber direction, stacking arrangements, material properties. In this theory, for plate analysis the Kirchhoff's plate theory is assumed and contains the assumptions as follows. This theory deals the mechanics of composite laminated plates using stress strain relations.

\section{Assumptions}

Straight lines perpendicular to the mid surface before deformation straight after deformation.

The transverse normal's do not experience elongation.

Transverse normal's rotate such that they remain perpendicular to the mid surface after deformation.

\section{Assumptions}

The layers are perfectly bonded together.

The material of each layer is linearly elastic and has three planes of material symmetry.

Each layer is of uniform thickness.

The strains and displacements are small.

The transverse shear stresses on the top and bottom of surfaces of the laminate are zero.

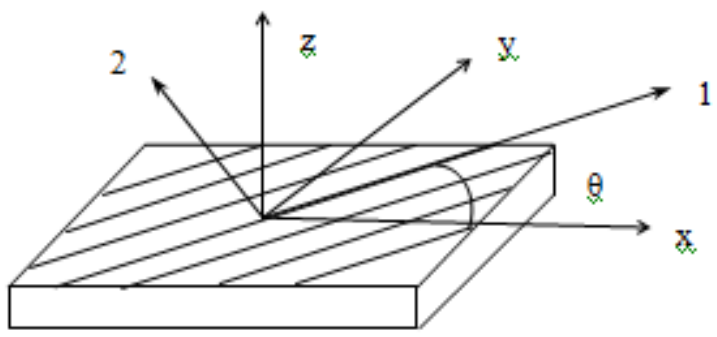

Figure 1: Composite Lamina

The above figure shows a composite lamina. The direction along the fiber axis is referred 1. The direction transverse to the fiber axis but in the plane of the lamina is refereed 2 . The direction transverse to both the fiber axis and the plane of the lamina (out of page) is referred 3 . 


\section{International Journal of Science and Research (IJSR) \\ ISSN (Online): 2319-7064}

Index Copernicus Value (2013): 6.14 | Impact Factor (2015): 6.391

The 1-2 co-ordinate system can be considered to be local coordinates based on the fiber direction. However this system is in adequate as fibers can be placed at various angles with respect to each other and the structure. Therefore a new coordinate system needs to be defined that takes into account the angle the fiber makes with its surroundings. This new system is referred to as global co-ordinates ( $x-y$ system) and is related to the local coordinates (1-2 system) by the angle $\theta$.

A composite material is not isotropic and therefore its stresses and strains cannot be related by the simple Hooke's Law. This law has to be extended to two-dimensions and redefined for the local and global co-ordinate systems. The result is Equations (1) and (2).

$$
\begin{aligned}
& {\left[\begin{array}{l}
\sigma_{1} \\
\sigma_{2} \\
\tau_{12}
\end{array}\right]=\left[\begin{array}{ccc}
Q_{11} & Q_{12} & 0 \\
Q_{21} & Q_{22} & 0 \\
0 & 0 & Q_{66}
\end{array}\right]\left[\begin{array}{l}
\varepsilon_{1} \\
\varepsilon_{2} \\
\gamma_{12}
\end{array}\right]} \\
& {\left[\begin{array}{c}
\sigma x \\
\sigma y \\
\tau x y
\end{array}\right]=\left[\begin{array}{lll}
\overline{Q_{11}} & \overline{Q_{12}} & \overline{Q_{16}} \\
\overline{Q^{21}} & \overline{Q^{22}} & \overline{Q_{26}} \\
\overline{Q_{26}} & \overline{Q_{66}}
\end{array}\right]\left[\begin{array}{l}
\varepsilon_{x} \\
\varepsilon_{y} \\
\gamma_{x y}
\end{array}\right]}
\end{aligned}
$$

Where $\sigma_{1,2}$ are the normal stresses in directions 1 and $2 ; \tau_{12}$ is the shear stress in the 1-2 plane; $\varepsilon_{1,2}$ are the normal strains in directions 1 and $2 ; \gamma_{12}$ is the shear strain in the $1-2$ plane. $[Q]$ is the reduced stiffness matrix; $\sigma_{x, y}$ are the normal stresses in directions $x$ and $y ; \tau_{x y}$ is the shear stress in the $x-y$ plane; $\varepsilon_{x, y}$ are the normal strains in directions $\mathrm{x}$ and $\mathrm{y} ; \gamma_{\mathrm{xy}}$ is the shear strain in the $x-y$ plane; is the transformed reduced stiffness matrix. The elements of the $[Q]$ matrix in Equation (1) are dependent on the material constants and may be calculated using Equations (3).

$$
\begin{array}{ll}
Q_{11}=\frac{E_{1}}{1-v_{12} v_{21}} & Q_{22}=\frac{E_{2}}{1-v_{12} v_{21}} \\
Q_{12}=\frac{v_{2} E_{1}}{1-v_{2} v_{21}} & Q_{66}=G_{12}
\end{array}
$$

Where $\mathrm{E}_{1,2}$ are Young's modulus in directions 1 and $2 ; G_{12}$ is the shear modulus in the 1-2 plane; $v_{12,21}$ are Poisson'sratios in the 1-2 and 2-1 planes

The $[\bar{Q}]_{\text {matrix }}$ in Equation (2) may be determined by Equation (4).

$$
[\overline{Q i j}]=[T]^{-1}[Q][R][T][R]^{-1}
$$

Where $[T]$ is the transformation matrix; $[R]$ is the Reuter matrix. These matrices are given by:

$$
[T]=\left[\begin{array}{ccc}
m^{2} & n^{2} & 2 m n \\
n^{2} & m^{2} & 2 m n \\
-m n & m n & m^{2}-n^{2}
\end{array}\right] \quad[R]=\left[\begin{array}{lll}
1 & 0 & 0 \\
0 & 1 & 0 \\
0 & 0 & 2
\end{array}\right] \text { (5) }
$$

And A, B and D matrices are known as extensional, coupling and bending laminate stiffness

$$
\begin{aligned}
A_{i j} & =\sum_{k=1}^{N}\left(\overline{Q_{i j}}\right)_{k}\left(z_{k}-z_{k}-1\right) \\
B_{i j} & =\frac{1}{2} \sum_{k=1}^{N}\left(\overline{Q_{i j}}\right)_{k}\left(z_{k}^{2}-z_{k-1}^{2}\right) \\
D_{i j} & =\frac{1}{3} \sum_{k=1}^{N}\left(\overline{Q_{i j}}\right)_{k}\left(z_{k}^{3}-z_{k-1}^{3}\right)
\end{aligned}
$$

hear $\mathrm{k}$ is no of layer and $\mathrm{Z}_{\mathrm{k}}$ terms are through thicknesses.

The orthotropic layers are oriented such that the complete laminate is symmetric across the middle surface. Due to this symmetry, the $[\mathrm{B}]$ matrix that relates the bending-extension coupling is effectively zero, $[\mathrm{B}]_{\mathrm{ij}}=0$. The $\mathrm{Z}_{\mathrm{k}}$ terms are defined from the middle surface of the laminate as shown in Figur

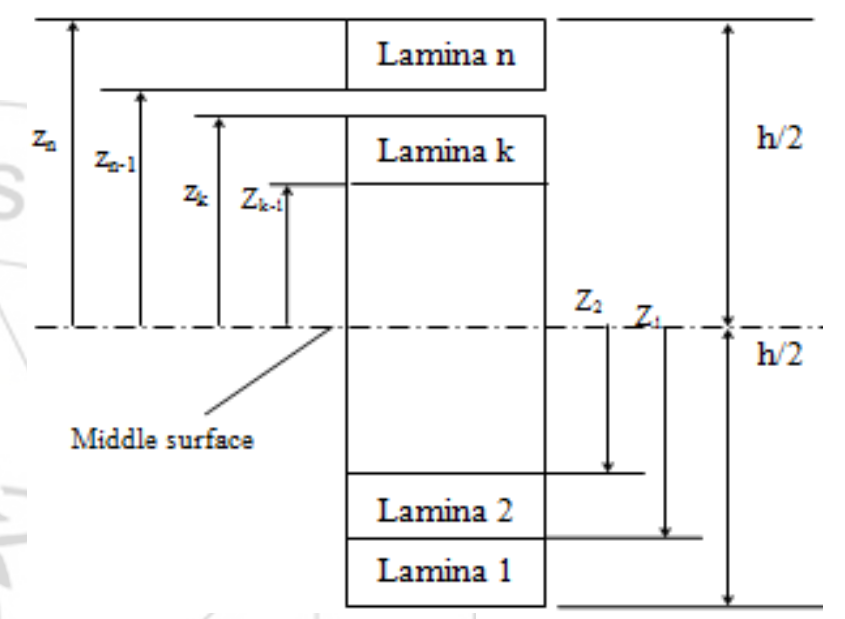

Figure 2: Locations of layers in composite laminate

\subsection{Effective Elastic properties of laminates}

From the test book of engineering mechanics of composite materials by M.Daniel ori ishai [3], It is important to calculate the Effective elastic properties of a Laminate, those are the effective extensional modulus in the $x$ direction, the effective extensional modulus in the $y$ direction, the effective Poisson's ratios and, and the effective shear modulus in the $\mathrm{x}-\mathrm{y}$ plane. These constants allow us to do classical mechanics of laminates like stress analysis and buckling analysis.

$$
\begin{aligned}
& \overline{E_{x}}=\frac{1}{a_{1} h} \quad \overline{E_{y}}=\frac{1}{a_{22} h} \quad \overline{G_{x y}}=\frac{1}{a_{66} h} \\
& \bar{K}_{x y}=\frac{a_{12}}{a_{1}} \quad, \overline{\bar{W}_{x}}=\frac{a_{12}}{a_{22}}
\end{aligned}
$$

Hear $a_{i j}$ is elements of compliance matrix, $\mathrm{h}$ is the laminate thickness.

In order to calculate the engineering properties of a symmetric laminate using above equations one needs to calculate the extensional stiffness matrix $[\mathrm{A}]$ and then invert it to obtain the compliance matrix $[a]$

$$
[a]=\left[\mathrm{A}^{-1}\right]
$$

\subsection{Free vibration of composite laminated plates}

hear $\mathrm{m}=\cos \theta, \mathrm{n}=\sin \theta$ and $\theta$ is ply angle. 


\section{International Journal of Science and Research (IJSR) \\ ISSN (Online): 2319-7064}

Index Copernicus Value (2013): 6.14 | Impact Factor (2015): 6.391

The laminated plates are widely used in aircraft structures because composites have high strength to stiffness ratio and low weight. To avoid the resonance for structures like aircraft we need to formulate the mathematical model for natural frequency for different types of laminated plates (symmetric, anti symmetric ...etc[2]). Generally we prefer symmetric laminated plate because of not having tendency to bend and twist. In order to formulate the mathematical formula for free vibration of laminated plates we need to develop governing equation, those equations are already developed by theories like classical laminate plate theory, shear deformation theory ...etc[1] using deflection, bending, forces and moments acting on laminate plate. In this thesis we consider CLPT.

These equations are solved by using analytically or numerically [1]. In analytical approach we have methods like Ritz, Levy and Navier. These methods are used according to the boundary conditions of the plate and easy usage. The Navier solution was developed for laminated plates (square or rectangular) when all the four edges are simply supported, Levy solution was developed for plates when two opposite edges are simply supported and remaining two edges are free, simply support or fixed support and Ritz solution was developed to determine the approximate solution for more general boundary conditions[1]. In this thesis we use Navier solution for the free vibration analysis of laminated plate under simply supported boundary conditions.

Consider a rectangular laminated plate of length a and width $\mathrm{b}$ having displacements in $\mathrm{x}, \mathrm{y}$ and $\mathrm{z}$ directions are $\mathrm{u}, \mathrm{v}$ and w respectively

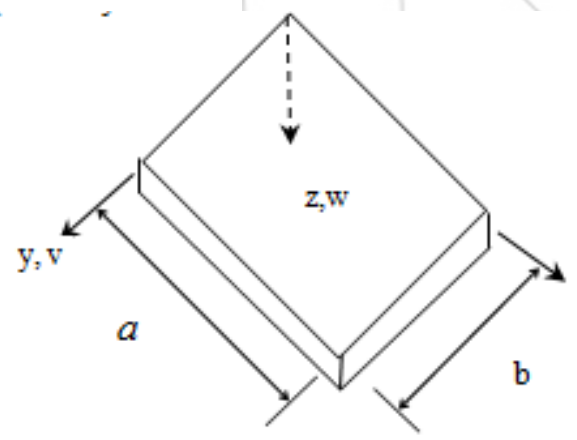

Figure 3: Plate Geometry and Displacement

Let us consider the composite laminated plate is under simply supported, the boundary conditions for the plate are shown in below.

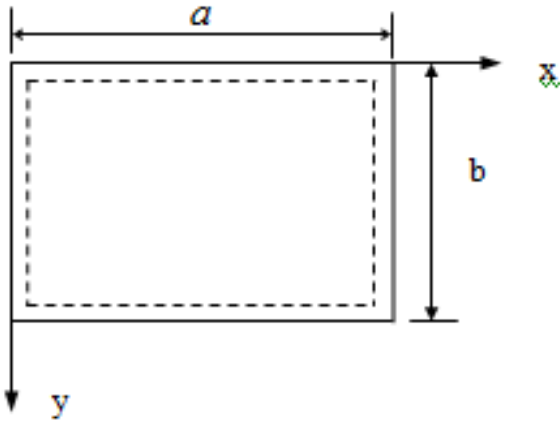

$x$

at $\mathrm{x}=0 \quad w_{\mathrm{o}}=\mathrm{M}_{\mathrm{xx}}=0$

at $\mathrm{x}=a \quad w_{\mathrm{0}}=\mathrm{M}_{\mathrm{xx}}=0$

at $\mathrm{y}=0 \quad w_{\mathrm{o}}=\mathrm{M}_{\mathrm{yy}}=0$

at $\mathrm{y}=b \quad w_{\mathrm{o}}=\mathrm{M}_{\mathrm{yy}}=0$

hear $\mathrm{a}$ and $\mathrm{b}$ are the length and width of plate

$w_{0}$ is deflection

$\mathrm{M}_{\mathrm{xx}}, \mathrm{M}_{\mathrm{yy}}$ are moments in $\mathrm{x}$ and $\mathrm{y}$ directions

The natural frequency of rectangular symmetric composite Plate having length $a$ and width $b$ is

$$
\omega_{n n}^{2}=\frac{\pi^{4}}{I_{0} b^{4}}\left[D_{11} m^{4}\left(\frac{b^{4}}{a^{4}}\right)+2\left(D_{12}+2 D_{56}\right) m^{2} n^{2}\left(\frac{b^{2}}{a^{2}}\right)+D_{22} n^{4}\right]
$$

Hear $I_{0}$ is the moment of inertia and is calculated using

$$
I_{0}=\sum_{k=1}^{N} \rho^{(K)}\left(z_{k+1}-z_{k}\right)
$$

The non dimensional frequency is

$$
\overline{\omega_{m n}}=\omega_{m n}\left(\frac{b^{2}}{\pi^{2}}\right) \sqrt{\frac{\rho h}{D_{22}}}
$$

Hear $b$ is width, is density of the composite material and $h$ is laminate thickness.

\section{Methodology}

The orthotropic symmetric laminated plate (4 layers) is Graphite epoxy was taken for the study, and its properties are Young's modules in longitudinal ply direction $\left(E_{1}\right)=20 \mathrm{Gpa}$ Young's modules in lateral ply direction $\left(\mathrm{E}_{2}\right)=2 \mathrm{Gpa}$

Shear modules $\left(\mathrm{G}_{12}\right)=1 \mathrm{Gpa}$

Poisson's ratio $\left(v_{12}\right)=0.25$

Density $(\rho)=1967 \mathrm{Kg} / \mathrm{m}^{3}$

Calculate the reduced stiffness matrix [Q] matrix for each layer using Equation (3)

Determine the transformed reduced stiffness matrix For each layer using Equation (4)

Calculate the extensional stiffness [A] ,coupling stiffness [B] and bending stiffness [D] matrices for laminate using Equation (6)

Calculate the natural frequency laminated plate under simply supported boundary condition using Equation (9).

Calculate the Non dimensional fundamental frequency of Laminated plate using Equation(11)

Calculate the inverse of $[\mathrm{A}]$ matrix i.e. $a=\left[\mathrm{A}^{-1}\right]$.

Calculate the effective elastic constants, those are the effective extensional modulus in the $x$ direction, the effective extensional modulus in the $y$ direction, the effective Poisson's ratios and, and the effective shear modulus in the $x-y$ plane using Equation (7).

Figure 4: Simply supported boundary condition of plate

The boundary conditions are 


\section{International Journal of Science and Research (IJSR) \\ ISSN (Online): 2319-7064}

Index Copernicus Value (2013): 6.14 | Impact Factor (2015): 6.391

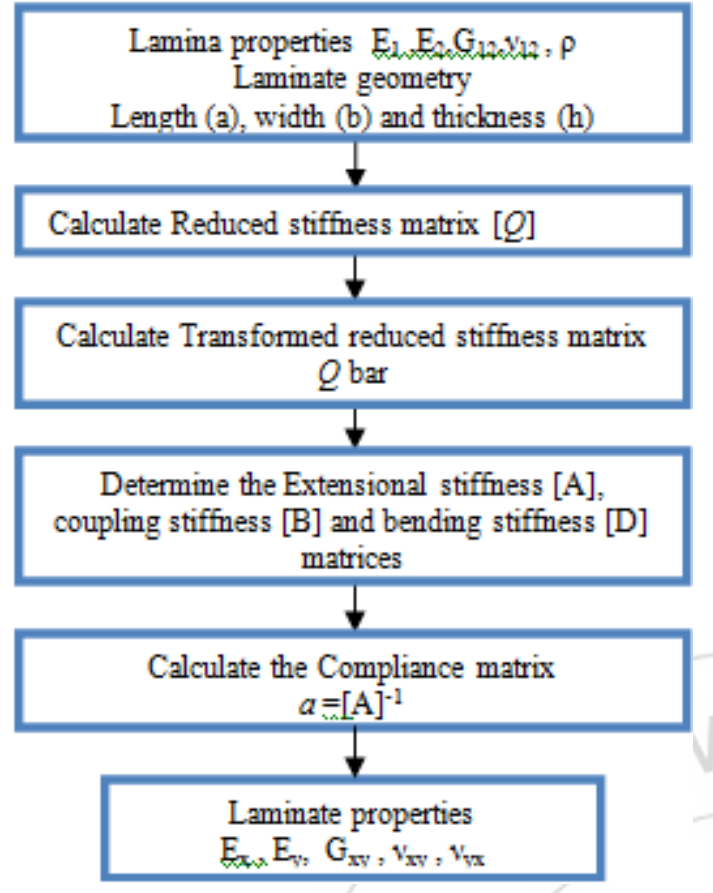

\section{Results}

Observed that

- For a square plate the natural frequency is maximum frequency for the $[\theta / 40]_{\mathrm{s}}$ and $[\theta / 50]_{\mathrm{s}}$ laminates and minimum for $[\theta / 0]_{\mathrm{s}}$ and $[\theta / 90]_{\mathrm{s}}$ laminates in every family of laminates.(hear $\theta=0,10,20,30,40,50,60,70,80,90) 25$ sets having same frequency.

- The non dimensional frequency is maximum for the laminates $[10 / 20]_{\mathrm{s}},[20 / 20]_{\mathrm{s}},[30 / 20]_{\mathrm{s}},[40 / 20]_{\mathrm{s}}$ (with respect to the family of laminates). And $[50 / 30]_{\mathrm{s}},[60 / 30]_{\mathrm{s}},[70 / 30]_{\mathrm{s}},[80 / 30]_{\mathrm{s}},[90 / 30]_{\mathrm{s}}$ are also maximum. the minimum frequency occurs for $[\theta / 90]_{\mathrm{s}}$ in every family.

- The natural frequency and laminate properties are satisfying the $6^{\text {th }}$ degree polynomials for all laminates having four layers. this condition also applicable for the laminates having 6 and 8 layers laminates.

- The natural and non-dimensional frequency will be decreased with increase of aspect ratio $(a / b)$. The frequency decreasing with increase of aspect ratio $a / b$ $(0.1 \mathrm{~m}$ to $1 \mathrm{~m}$ when $\mathrm{b}=1 \mathrm{~m})$ i.e frequency is decreasing drastically up to $\mathrm{a} / \mathrm{b}$ is 0.6 and then minor decreasing (almost linear).

- In case of effective elastic properties of laminates, the Ex and Ey values are equal for $\left[\theta_{1} / \theta_{2}\right]_{\mathrm{s}}$ laminates which are satisfy the condition $\theta_{1}+\theta_{2}=90$.In detail from effective elastic properties plots by family wise the first family i.e. $[0 / \theta]_{\mathrm{s}}$ and last series i.e. $[90 / \theta]_{\mathrm{s}}$ the plots are reserved i.e Ex tends to Ey, NUxy tends to NUyx (mirror image to each other).

- For the laminates which are having $E x=E y$ for that laminates the natural frequencys $(\mathrm{rad} / \mathrm{sec})$ and non dimensional frequency are tabulated below.
Table 1: Natural frequency $(\mathrm{rad} / \mathrm{sec})$

\begin{tabular}{|c|c|c|}
\hline$L a y-U p$ & Maximum & Minimum \\
\hline $\begin{array}{llll}0 & 90 & 90 & 0\end{array}$ & ----- & First minimum 10.584 \\
\hline $1080 \quad 80 \quad 10$ & ------ & $\begin{array}{c}\text { Second minimum } \\
10.9677\end{array}$ \\
\hline $2070 \quad 70 \quad 20$ & ----- & $\begin{array}{c}\text { Thired minimum } \\
11.8841\end{array}$ \\
\hline $3060 \quad 60 \quad 30$ & $\begin{array}{c}\text { Second maximum } \\
12.847\end{array}$ & ------ \\
\hline $4050 \quad 50 \quad 40$ & $\begin{array}{c}\text { First maximum } \\
13.4384\end{array}$ & - \\
\hline $5040 \quad 40 \quad 50$ & $\begin{array}{c}\text { First maximum } \\
13.4384\end{array}$ & -- \\
\hline $60 \quad 30 \quad 30 \quad 60$ & $\begin{array}{c}\text { Second maximum } \\
12.847\end{array}$ & $\ldots$ \\
\hline $\begin{array}{llll}70 & 20 & 20 & 70\end{array}$ & ------ & $\begin{array}{c}\text { Thired minimum } \\
11.8841\end{array}$ \\
\hline $\begin{array}{llll}80 & 10 & 10 & 80\end{array}$ & ----- & $\begin{array}{c}\text { Second minimum } \\
10.9677\end{array}$ \\
\hline $90 \quad 0 \quad 0 \quad 90$ & $\begin{array}{l}----- \\
---\end{array}$ & First minimu 10.584 \\
\hline
\end{tabular}

Table 2: Non dimensional frequency

\begin{tabular}{|cccc|c|c|}
\hline \multicolumn{4}{|c|}{ Lay-Up } & Maximum & Minimum \\
\hline 0 & 90 & 90 & 0 & ---- & $\begin{array}{c}\text { First minimum } \\
2.5193 \\
\text { (J.N Reddy })\end{array}$ \\
\hline 10 & 80 & 80 & 10 & ----- & $\begin{array}{c}\text { Second minimum } \\
2.639\end{array}$ \\
\hline 20 & 70 & 70 & 20 & ----- & $\begin{array}{c}\text { Thired minimum } \\
2.8905\end{array}$ \\
\hline 30 & 60 & 60 & 30 & ----- & $\begin{array}{c}\text { fourth minimum } \\
2.9943\end{array}$ \\
\hline 40 & 50 & 50 & 40 & ---- & $\begin{array}{c}\text { Fifth minimum } \\
2.7621\end{array}$ \\
\hline 50 & 40 & 40 & 50 & ---- & $\begin{array}{c}\text { Sixth minimum } \\
2.3251\end{array}$ \\
\hline 60 & 30 & 30 & 60 & first maximum 1.8852 & ------- \\
\hline 70 & 20 & 20 & 70 & Thired maximum & ------ \\
\hline 80 & 10 & 10 & 80 & Fourth & ------- \\
\hline 90 & 0 & 0 & 90 & Fifth maximum 1.2328 & ------- \\
\hline
\end{tabular}

\section{Conclusion}

The graphite/epoxy composite laminates of four layers having lay up configarations of $[40 / \theta]_{\mathrm{S}}$ and $[50 / \theta]_{\mathrm{s}}$ square plates are recommended for aero space structures because of it's highest natural frequency to avoid resonance under simply supported boundary conditions. For these lay up configarations the laminate properties are also intermediate. For rectangular plates the natural frequency shows maximum for $[0 / \theta]_{\mathrm{s}}$. The non dimensional frequency is maximum for $[20 / \theta]_{\mathrm{s}}$ square plate. Effective youngs modulus of laminate in the global $\mathrm{x}$ direction $\left(\mathrm{E}_{\mathrm{x}}\right)$ is maximum for $[0 / 0]_{\mathrm{s}}$ laminate. Effective youngs modulus of laminate in the global $y$ direction $\left(E_{y}\right)$ is maximum for [90/90]s laminate. Effective shear modulus in the global $x y$ plane $\left(G_{x y}\right)$ is maximum for $[40 / 0]_{\mathrm{s}}$ laminate. 


\section{International Journal of Science and Research (IJSR) \\ ISSN (Online): 2319-7064}

Index Copernicus Value (2013): 6.14 | Impact Factor (2015): 6.391

The analytical results are compared with the AUTODESK simulation composite design 2014 software and getting good agreement, the error is very minor. The natural frequency is decreesing with incress in aspect ratio $(\mathrm{a} / \mathrm{b})$ for all 100 samples of laminates.the effective elastic properties are not vary with change in aspect ratio $(\mathrm{a} / \mathrm{b})$ and laminate thickness (h)

\section{Co-relation between Natural frequency and laminate properties}

By series wise

E BAR X - Effective extensional modulus in the ' $\mathrm{X}$ ' direction $(\mathrm{GPa})$

E BAR X - Effective extensional modulus in the ' $y$ ' direction $(\mathrm{GPa})$

G BAR XY - Effective shear modulus (GPa) NF - Natural frequency ( $\mathrm{Rad} / \mathrm{sec})$

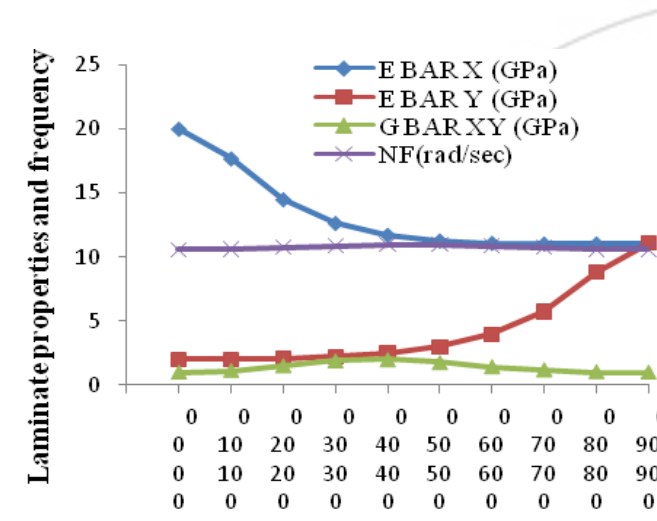

Lay-up (deg)

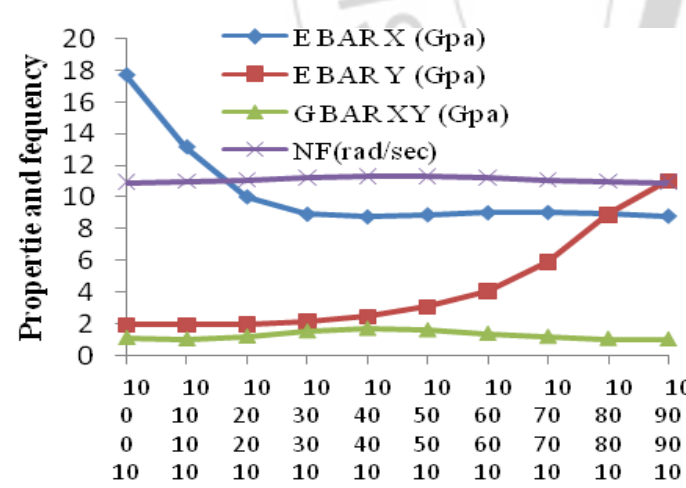

Lay-up (deg)
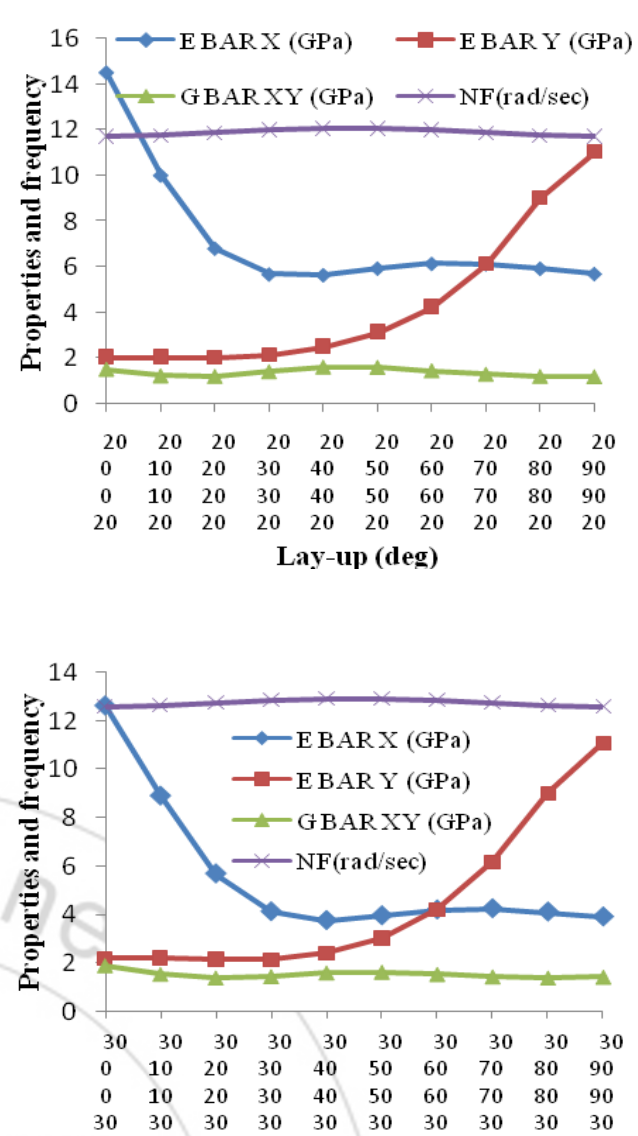

Lay-up (deg)

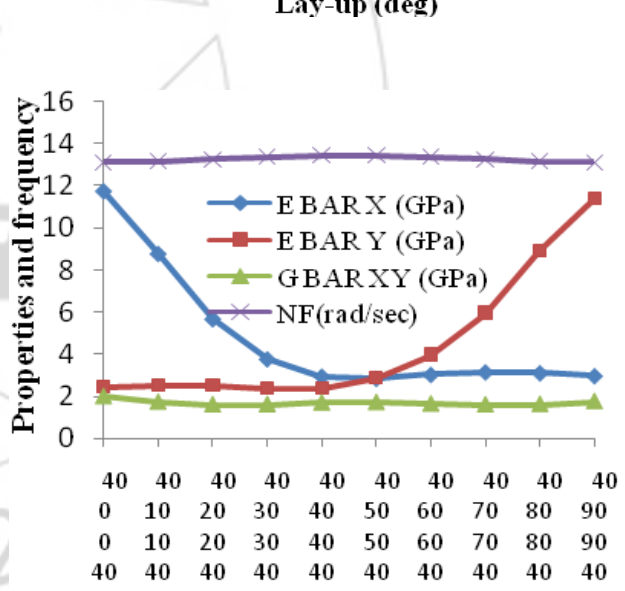

Lay-up (deg)

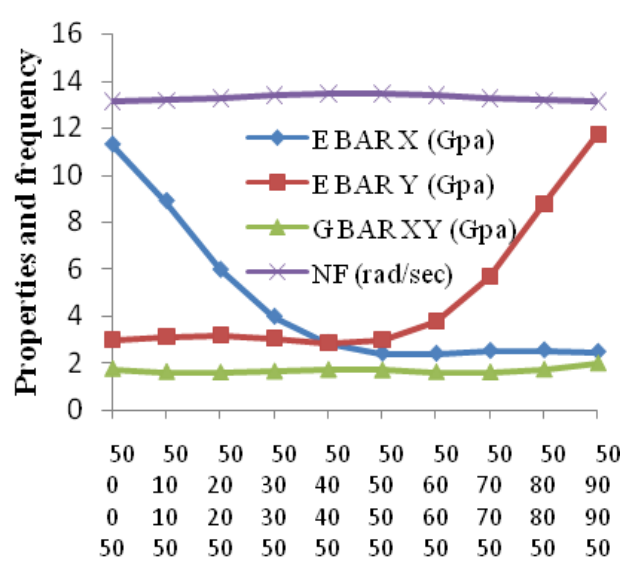

Lay-up (deg) 


\section{International Journal of Science and Research (IJSR) \\ ISSN (Online): 2319-7064}

Index Copernicus Value (2013): 6.14 | Impact Factor (2015): 6.391

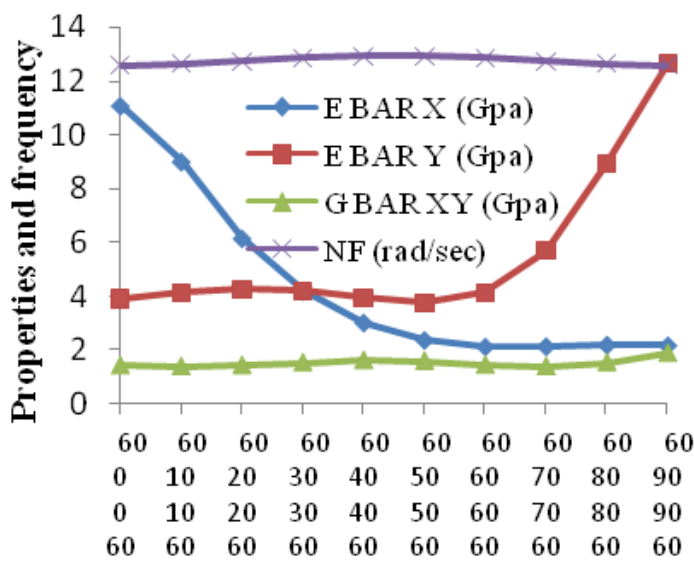

Lay-up (deg)

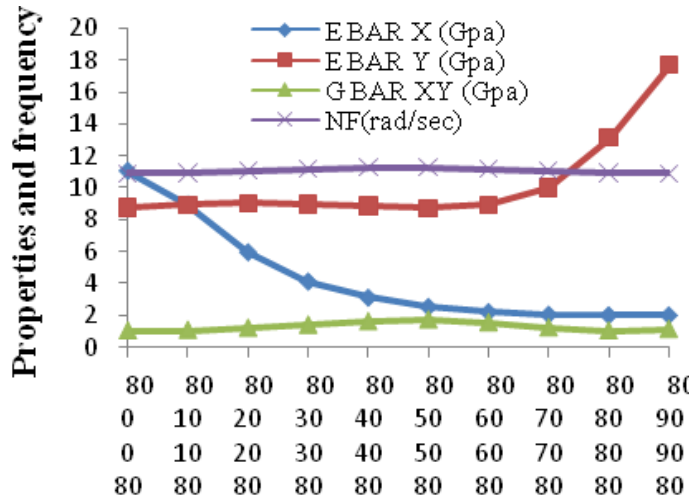

Lay-up (deg)
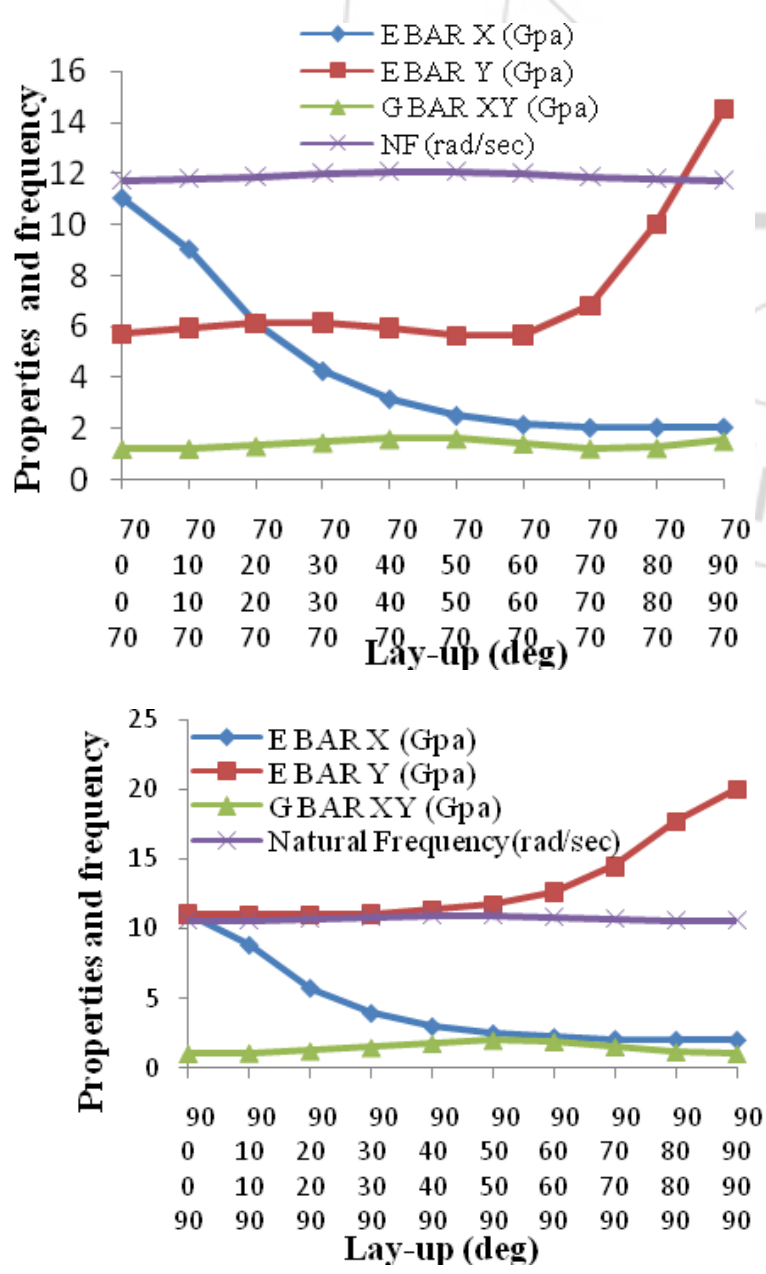

\section{References}

[1] JN Reddy "Mechanics of Laminated Composite Plates and Shells"

[2] The basic mechanics of of composite materials are from "Mechanics of Composite materials by Robert M.Jones"

[3] Engineering mechanics of composite materials by Isaac M.Daniel Ori ishai

[4] Mutra Raja Sekhara Reddy, Bathini Sidda Reddy, Vanguru Nageswara Reddy, Surisetty Sreenivasulu"Prediction of Natural Frequency of Laminated Composite Plates Using Artificial Neural Networks"journal of scientific research 2012

[5] S. K. Sahu P. K. Datta"Dynamic instability of laminated composite rectangular plates subjected to non- uniform harmonic in-plane edge loading" 2000 journal of aerospace engineering

[6] R.A. Jafari-Talookolaei and M.T.Ahmadian "Free Vibration Analysis of a Cross-Ply Laminated Composite Beam on Pasternak Foundation"Journal of Computer Science 2007

[7] B. Sidda Reddy1, M. Raja Sekhara Reddy, V. Nageswara Reddy "Vibration Analysis Of Laminated Composite Plates Using Design Of Experiments approach"International Journal of Scientific Engineering and Technology 2013

[8] Rengin Kayikci, Fazil O. Sonmez"Design of composite laminates for optimum frequency response"ELSEVIER 2012

[9] Md Iftekhar Alam, Tasmeem Ahmad Khan "Comparative Analysis of Multi Layered Composite Plates using Higher Order Theories"International Journal of Science and Research (IJSR) 2013

[10] Mechanics of Laminated Composite Plates and Shells by JN Reddy page no 284

[11] The basics of of free vibration and buckling analysis of composite plates under simply supported boundary conditions are from"Mechanics of Laminated Composite Plates and Shells by JN Reddy page no 271-285"

[12] Kanak Kalita and Abir Dutta "Free vibration Analysis of Isotropic and Composite Rectangular Plates" International Journal of Mechanical Engineering and Research2013

[13] T.kant, K.swaminathan "Analytical solutions for free vibration of laminated composite and sandwich plates based on higher- order refined theory" ELSEVIER 2001

[14] Hiroyuki Matsunaga "Vibration of cross- ply laminated composite plates subjected to initial in-plane stress" ELSEVIER 2002

[15]H. Nguyen-Van , N. Mai-Duy ,T. Tran-Cong "Free vibration analysis of laminated plate/shell structures based on FSDT with a stabilized nodal-integrated quadrilateral element" ELSEVIER 2007

[16] Y.X. Zhang a, *, C.H. Yang "Recent developments in finite element analysis for laminated composite plates" ELSEVIER 2009 